\title{
Milliliter per Gram per Minute
}

National Cancer Institute

\section{Source}

National Cancer Institute. Milliliter per Gram per Minute. NCI Thesaurus. Code C73757.

A dose calculation unit expressed in milliiter(s) per gram per period of time equal to sixty seconds. 